\title{
CULTURA ESCRITA EN LA SOCIEDAD DEL SOFTWARE ${ }^{1}$
}

WRITING CULTURE IN THE SOCIETY OF SOFTWARE

CULTURA ESCRITA NA SOCIEDADE DO SOFTWARE

140

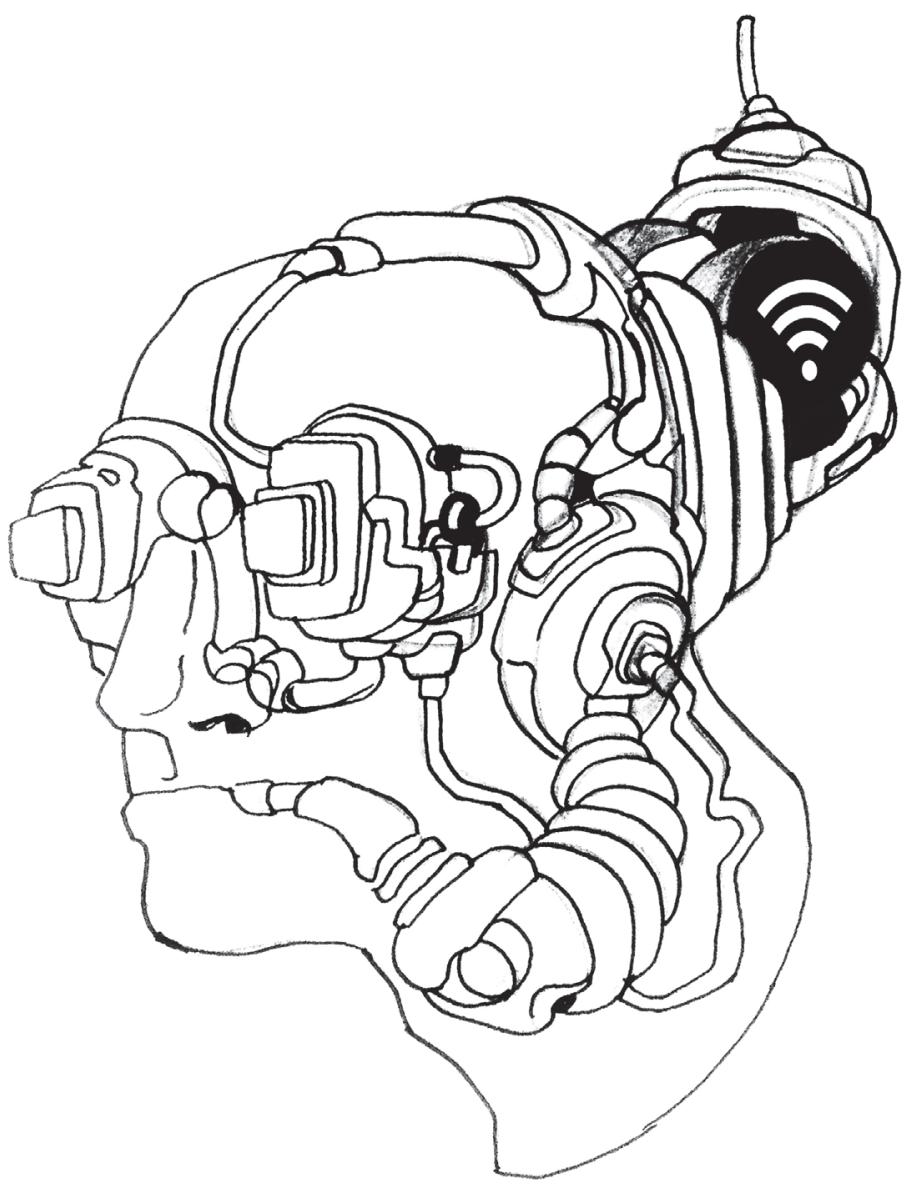

Por

Giovanna Carvajal Barrios ${ }^{2}$

Profesora de la Escuela de Comunicación Social

Universidad del Valle

giovanacarv@hotmail.com

Resumen: El artículo forma parte de una investigación sobre las transformaciones de la cultura escrita en el ciberespacio. En él se reseñan los planteamientos de Lev Manovich (2013) sobre la cultura del software para articularlos a la conceptualización de la cultura escrita y sus conocimientos procedimentales (Ulloa y Carvajal, 2006) y a la emergencia de conocimientos procedimentales en el escenario de la redes sociales, como parte de las transformaciones en curso.

Palabras clave: Software de medios, escritura digital, cultura escrita, conocimientos procedimentales para leer y escribir, escritura en las redes sociales. 
Abstract: This paper is part of a research on the transformations of writing culture in cyberspace. Lev Manovich's ideas on software culture are reviewed in order to connect them to the concepts of writing culture and its procedural knowledges (Ulloa y Carvajal, 2006), and to the emergence of procedural knowledges in the scene of social media, as part of the ongoing transformations.

Keywords: Media software, digital writing, writing culture, procedural knowledge to read and to write, writing in social media.

Resumo: $\mathrm{O}$ artigo faz parte de uma pesquisa sobre as transformações da cultura escrita no ciberespaço. Nele são revisadas as ideias de Lev Manovich (2013) sobre a cultura do software e são articuladas à conceitualização da cultura escrita e os seus conhecimentos procedimentais (Ulloa e Carvajal, 2006) e à emergência de conhecimentos procedimentais no cenário das redes sociais, como parte das transformações que vêm ocorrendo.

Palavras-chave: Software de meios, escritura digital, cultura escrita, conhecimentos procedimentais para ler e escrever, escritura nas redes sociais.

En su libro "El software toma el mando", Lev Manovich (2013) señala la presencia del software en casi la totalidad de ámbitos de la sociedad actual. El flujo permanente que caracteriza el mundo del software contrasta con la lentitud de los cambios que caracterizaron la maquinaria de la sociedad industrial y es -en conexión con otros rasgos que se expondrán más adelante- lo que ha contribuido a configurar una condición cultural de la actualidad, a la que Manovich denomina -utilizando un neologismo de su autoría- "softwarización de la cultura" (Manovich, 2013, p. $21^{3}$ ). Dicha condición no resulta ajena al ámbito de la cultura escrita, en lo que respecta a sus prácticas, sus herramientas y los conocimientos que le son propios.

El objetivo central del libro de Manovich es abordar el "software de medios" (o "software de autoría de medios"), un tipo particular de software que se encuentra conectado con la creación, el acceso y la distribución de contenidos almacenados en medios. El autor analiza sus orígenes, las ideas que lo hicieron posible, los rasgos que lo caracterizan, y se pregunta por su incidencia en la estética contemporánea y en los lenguajes gráficos de la actualidad. En sus planteamientos teóricos -enmarcados en el naciente campo de estudios del software- no se encuentra presente la noción de cultura escrita (perteneciente a un campo de estudios que no es el suyo). No obstante, a lo largo de su exposición menciona la escritura como uno de los ámbitos que está atravesado por la presencia de un tipo particular de software, conocido como procesador de textos, y hace referencia a las redes sociales como lugares donde hace presencia el software. Su interés central está en caracterizar el software, señalando las posibilidades que proporciona en tanto metamedio que no sólo simula, sino que remoldea los medios tradicionales y genera medios antes inexistentes. 
La "teoría de la cultura del software" de Manovich (2013, p. 311) es pertinente para la investigación sobre las transformaciones de la cultura escrita en el ciberespacio, por tres razones: en primer lugar, el ciberespacio (Lévy, 2007) no hubiese sido posible sin la invención y el desarrollo del software. Hablar del ciberespacio implica -necesariamente- hablar del software que le da existencia. En segundo lugar, tanto la escritura en ordenador -sin conexión a la red-como la que se funda en la conexión (por ejemplo la realizada para el chat, el Facebook o el Twitter) requieren un software para llevarse a cabo. En tercer lugar, en concordancia con los propósitos de la investigación, interesa identificar si algunos de los rasgos que adquieren la escritura y la lectura en el ciberespacio - particularmente en los tres escenarios analizados- se relacionan con los condicionamientos y posibilidades derivados de las herramientas y recursos proporcionados por el software de medios. Se trataría de ver en qué medida la "omnipresencia del software" de la que habla Manovich (2013, p. 19) se expresa en la cultura escrita, particularmente en los escenarios de comunicación que son objeto del presente estudio.

\section{Tipos de software: software cultural, software social}

El software de sistemas, las herramientas de programación informática, los servicios y tecnologías de las redes sociales y el software para aplicaciones (del cual forma parte el software de medios) son mencionados por el autor como ejemplos de los tipos de software existentes. Una categoría general que engloba diferentes tipos de software es la llamada "software cultural". Con esta denominación el autor se refiere a aquellos "tipos de software que sirven de base para una serie de acciones que solemos asociar con la cultura”. Acciones que, para Manovich, pueden dividirse en varias categorías (Manovich, 2013, p. 42):

1. "Crear objetos culturales y servicios interactivos que contengan representaciones, ideas, creencias y valores estéticos”.

2. "Acceder, adjuntar, compartir y re mezclar dichos objetos (o sus componentes) por internet”.

3. "Crear y compartir información y conocimientos por internet".

4. "Comunicarse con otros".

5. "Participar de experiencias culturales interactivas".

6. "Formar parte de la ecología informativa por internet al expresar preferencias y añadir metadatos".

7. Desarrollar herramientas y servicios de software que sirvan de base para todas esas actividades.

Varias de las acciones mencionadas por el autor implican la presencia de la cultura escrita, como puede verse en algunos de los ejemplos citados por él: leer periódicos o revistas virtuales y añadir comentarios en un blog (segunda acción); corregir artículos de la Wikipedia (tercera acción); enviar correos electrónicos, escribir en el chat y publicar escritos en el muro de Facebook (cuarta acción); "retuitear" una información (sexta acción) (Manovich, 2013, p. 42). 
Dentro de las subcategorías que forman parte del "software cultural" el autor otorga particular importancia al "software social”, al que pertenecen las herramientas diseñadas para comunicar y compartir información y conocimientos (v.g. motores de búsqueda, navegadores web, editores de blogs, aplicaciones para email, aplicaciones para mensajería instantánea, wikis, marcadores sociales, redes sociales, mundos virtuales, mercados de predicción) y las herramientas de software para gestión de información personal (gestores de proyectos, aplicaciones de bases de datos, editores de texto, tomas de nota). Según Manovich, estas herramientas se han extendido a tal punto, que podría decirse que todo el software ha devenido en software social (Manovich, 2013, p. 49).

Al software cultural también pertenecen los entornos de programación y las interfaces de medios (íconos, carpetas, sonidos, animaciones, superficies vibrantes, aportaciones de los usuarios) (Manovich, 2013, p.51).

Aunque Manovich reconoce que pueden existir distintos criterios para definir categorías de software, menciona otra categoría general que distingue el software dependiendo de los tipos de actividades desarrolladas a partir de él: por un lado, se encuentra el software que permite crear, editar y organizar contenido de medios, y por otro el software para distribuir, acceder, combinar, publicar, compartir y re mezclar contenidos ${ }^{5}$.

\section{Software de aplicaciones y software para medios}

El software de aplicaciones (subcategoría del software cultural) incluye las aplicaciones de sobre mesa (como Illustrator, Photoshop o After Effecs), las apps móviles (disponibles en dispositivos móviles) y las aplicaciones web (conformadas por un cliente web y un software ejecutado desde un servidor). El software para medios (o software para aplicaciones destinado a generar contenido y acceder a él) es una división del software de aplicaciones que "hace posible la creación, publicación, acceso, compartición y remezcla de distintos tipos de medios, como imágenes, secuencias de imagen en movimiento, formas tridimensionales, caracteres y espacios, textos, mapas, elementos interactivos, así como diferentes proyectos y servicios que hacen uso de estos elementos" (Manovich, 2013, p. 47-48). En cuanto a los proyectos, éstos pueden ser "no interactivos" o “interactivos", caso en el cual permiten la navegación e interacción con el contenido a través de una interface. Al último grupo pertenecen las páginas web, los blogs, las redes sociales, los servicios de medios sociales, los juegos, las wikis, los medios web y las tiendas de apps (Manovich, 2013, p. 47-48).

De las actividades que permite el software de medios, la creación -seguida de la remezclaes la que involucra directamente los conocimientos procedimentales de la cultura escrita. En cuanto al acceso, éste involucra los conocimientos procedimentales para leer en doble vía desde la perspectiva de la organización del texto (Ulloa y Carvajal,2008a). Compartir y publicar involucran tanto la lectura como la escritura, pues lo que se comparte ha sido leído con anterioridad y eventualmente es acompañado con un comentario propio. 


\section{El metamedio ordenador}

Como parte del recuento histórico realizado en la primera sección de su libro, el autor se remite al término "metamedio", acuñado por Kay y Gokldberg en 1977 (Kay y Gokldberg, citados por Manovich, 2013, p. 152) para referirse al ordenador digital. Este dispositivo inventado a mediados de los años 40 llegaría a convertirse en algo más que una máquina versátil para crear y editar textos, hacer dibujos, mover un objeto virtual, etc. y su manejo llegaría a estar al alcance de la gente del comúngracias a la creación de la interfaz gráfica de usuario-- Todos esos avances permitieron que el ordenador se convirtiera, según lo declarado por Kay y Gokldberg, en "algo cualitativamente distinto e históricamente sin precedentes" (Kay y Gokldberg, 1977, citados por Manovich, 2013, p. 143).

Para el autor, los metamedios constituyen "un sistema semiótico y tecnológico esencialmente nuevo que incorpora la mayoría de técnicas y estéticas de los medios anteriores, así como sus elementos" (p. 117). Su contenido es el conjunto de medios ya existentes y los que están por inventarse (Kay y Goldberg, 1977, citados por Manovich, 2013, p. 152). La novedad de los metamedios no se encuentra en el contenido, sino en las herramientas de software empleadas para crear, editar, visualizar, distribuir y compartir contenido. De igual modo, dicha novedad es posible gracias a la posibilidad de añadir constantemente nuevas propiedades (nuevas técnicas de software) en una dinámica de ampliación y redefinición constante (Manovich, 2013, p.130).

En cuanto a los tipos de medios que contiene el metaordenador, el autor distingue dos: por una parte, las simulaciones de medios físicos previos, a los cuales se dota de nuevas propiedades; y por otra parte, los medios informativos que no cuentan con precedentes físicos, es decir, los "nuevos medios" en sentido estricto: hipertexto e hipermedia, espacios tridimensionales navegables e interactivos y multimedia interactiva, atribuidos a Ted Nelson, Ivan Sutherland y a los colectivos "Architecture Machine group" y "Aspen Movie Map”, respectivamente. (Manovich, 2013, p. 153)

"Remediar" o representar medios anteriores significa que los medios tradicionales o antiguos (el lenguaje escrito, el sonido, los dibujos lineales y los planos de diseño, las pinturas y las fotografías) son utilizados como "contenido en bruto" de los metamedios; en otras palabras, son usados "como pilares para crear unas estructuras de representación e información anteriormente inimaginables, unas herramientas creativas y de pensamiento, así como opciones de comunicación" (Manovich, 2013, p. 135). Al hacerlo, los metamedios propician un entorno distinto para dichos medios y los refuerzan con muchas propiedades de nueva creación” (Manovich, 2013, p. 144).

Pero para Manovich "la propiedad más importante desde el punto de vista de la historia de los medios es que el metamedio ordenador es, a la vez, un conjunto de medios diferentes y un sistema para la generación de nuevas herramientas para medios y nuevos tipos de medios. Es decir, se puede usar un ordenador para crear nuevas herramientas que permitan trabajar con los tipos de medios que ya proporciona, pero también desarrollar nuevos medios aún por inventar" (Manovich, 2013, p. 144). 
La configuración del metamedio ordenador se fundamenta en dos estructuras básicas: La primera son los tipos de datos de medios (entre los que se cuentan el texto, las imágenes vectoriales y las secuencias de esas imágenes -animación vectorial-, las imágenes de tono continuo y secuencias de esas imágenes -fotografías y video digital, los modelos en 3D, los datos geoespaciales y el audio). La segunda son las técnicas para generar, modificar y visualizar dichos datos (Manovich, 2013, p. 153). En cuanto a las técnicas, se encuentran de dos clases: las técnicas para un medio, es decir para tipos concretos de datos, y las técnicas independientes del medio, las cuales funcionan con datos digitales en general. Entre estas últimas el autor menciona el control de visualización, los hipervínculos, las herramientas para ordenar y buscar, y las opciones de copiar y pegar.

El autor destaca que "las técnicas de software independientes del medio son ubicuas y 'universalistas'" (Manovich, 2013, p. 167), independientemente de si son aplicadas por el creador de un producto comunicativo o si quien las usa es alguien distinto a éste. En esta última circunstancia, Manovich alude a la capacidad técnica de acceder a fragmentos de las obras de medios realizados por otros como el principio básico de la principal estética de la época actual: la remezcla (Manovich, 2013, p. 167). Para el autor, el alcance y la importancia de las técnicas de software independientes del medio permite "compararlas con los principios básicos de organización de medios y objetos que se emplearon durante miles de años" (Manovich, 2013, p. 169). Lo que él caracteriza como la omnipresencia del software (p. 19) se hace evidente en un hecho concreto: las técnicas que funcionan con todo tipo de datos digitales "ayudan a conformar una misma visión de los medios" que corresponde a lo experimentado por los usuarios como "principios comunes de los medios", independientemente de su contenido (Manovich, 2013, p. 168). Lo anterior se sintetiza en una afirmación contundente del autor: "vivimos en una cultura del software, a saber, una cultura donde la producción, la distribución y la recepción de gran parte del contenido nos llegan mediadas por el software" (p. 65). En la actualidad, el software "desempeña un papel primordial a la hora de configurar tanto los elementos materiales como muchas de las estructuras inmateriales que, conjuntamente, conforman la 'cultura'” (Manovich, 2013, p. 57).

Más allá de la simulación de medios físicos ya existentes, lo que se ha logrado es la creación de medios con nuevas propiedades. La lista es extensa y la conforman, entre otras, la búsqueda y la manipulación dinámicas, la naturaleza no secuencial del medio archivo, la modificación de fuentes de un documento o creación de nuevas fuentes, el control de visualizaciones (que permite alternar distintas formas de visualizar la misma información), el uso de hipervínculos (que permite conectar partes de un documento y documentos entre sí), la colaboración de múltiples usuarios para construir un documento, el correo electrónico y la World Wide Web. 


\section{El software de medios: diez rasgos para su caracterización}

A partir de lo planteado por Manovich, se pueden formular diez rasgos que caracterizan el software de medios:

1. La remezclabilidad, que se aplica tanto a los contenidos como a las técnicas, métodos de trabajo y vías de representación y expresión. Manovich la denomina "remezclabilidad profunda" dado que no se limita a la mezcla de contenidos de distintos medios, propia de la actual cultura de la imagen en movimiento. "Unidos dentro del entorno del software compartido, los lenguajes de la cinematografía, la animación, la animación por ordenador, los efectos especiales, el diseño gráfico, la tipografía, el dibujo y la pintura han acabado formando un nuevo metalenguaje. Una obra producida en este nuevo metalenguaje puede utilizar todas las técnicas, o cualquier subconjunto, que en el pasado eran exclusivas de estos medios respectivos" (Manovich, 2013, p. 351).

2. La modularidad en dos niveles: como creación, distribución y reutilización de fragmentos de contenido, y como "principio fundamental de la creación de software moderno a la hora de diseñar programas informáticos a partir de pequeños componentes reutilizables llamados funciones o procedimientos" (Manovich, 2013, p. 46).

3. La ampliabilidad, consistente en la reinvención permanente de técnicas que conlleva a una constante redefinición del software (Manovich, 2013, p. 130).

4. La experimentación con los medios, que si bien durante la era industrial se presentaba en casos aislados, se convierte en norma para la sociedad del software (Manovich, 2013, p. 131).

5. La maleabilidad, rasgo que diferencia el software frente a los objetos producidos de forma industrial en el siglo XX (Manovich, 2013, p. 132). En palabras del autor, el mundo actual "no se define por pesadas maquinarias industriales que cambian muy de vez en cuando, sino por el software que se encuentra en un flujo permanente" (Manovich, 2013, p. 16).

6. La coexistencia de las funciones de autoría y acceso, cuyo ejemplo paradigmático lo constituyen el Word y el Power Point, programas utilizados para desarrollar contenidos como para acceder a ellos (Manovich, 2013, p. 49).

7. Tendencia a la eliminación de las fronteras entre programas de aplicación, sistema operativo y datos. Un ejemplo de ello lo constituye Facebook que se ha posicionado como una 'plataforma social total', es decir, capaz de abarcar distintos programas y servicios independientes de comunicación (Manovich, 2013, p. 50).

8. La hibridez, que trae como resultado "una nueva estética y una nueva "especie de medios' que no pueden reducirse a la suma de los medios que las componen”. Se trata de una fase posterior a la etapa de simulación de los medios físicos individuales en un ordenador. "Se manifiesta en distintos ámbitos de la cultura y no tan sólo en las imágenes en movimiento, aunque este último campo represente un ejemplo muy ilustrativo de esta nueva lógica cultural imperante" (Manovich, 2013, p. 349). 
9. La evolución constante, derivada de todos los rasgos anteriores. El concepto es retomado por Manovich de la biología, aunque como lo aclara, con él no pretende señalar "los mecanismos reales de evolución biológica de la Tierra tal como los han postulado y defendido los científicos (porque esos mecanismos no encajan en la evolución tecnológica y cultural), sino más bien la imagen de un desarrollo temporal gradual, pero continuo, y el aumento de la variabilidad y la especiación (aparición de nuevas especies) que implica esta idea, sin que ello suponga progreso" (Manovich, 2013, p. 313).

10 .La omnipresencia, la cual, según Manovich, se produce entre 1960 y 2010 en un proceso irreversible al que denomina la "softwarización de la cultura" (Manovich, 2013, p. 21). Este carácter omnipresente del software contrasta con el desconocimiento de su historia y de las ideas teóricas que dieron lugar a su desarrollo (Manovich, 2013, p. 19). Contrario a esta tendencia, Manovich considera que el estudio del software es un imperativo actual, dado que "a excepción de determinados ámbitos culturales, como las manualidades y las bellas artes el software ha reemplazado toda una serie de tecnologías físicas, mecánicas y electrónicas que antes del siglo XXI se empleaban para crear, almacenar, distribuir y acceder a los objetos culturales" (Manovich, 2013, p. 16). Escribir en un procesador de textos, colgar mensajes en Facebook, buscar videos en YouTube, implica el uso de un software (Manovich, 2013, 16). "El software se ha convertido en nuestra interfaz con el mundo, con los demás, con nuestra memoria y nuestra imaginación: un lenguaje universal que el mundo emplea para hablar y un motor universal que propulsa el mundo. Lo que representaron la electricidad y el motor de combustión para los primeros años del siglo XX es hoy el software para los primeros años del XXI" (Manovich, 2013, p. 16).

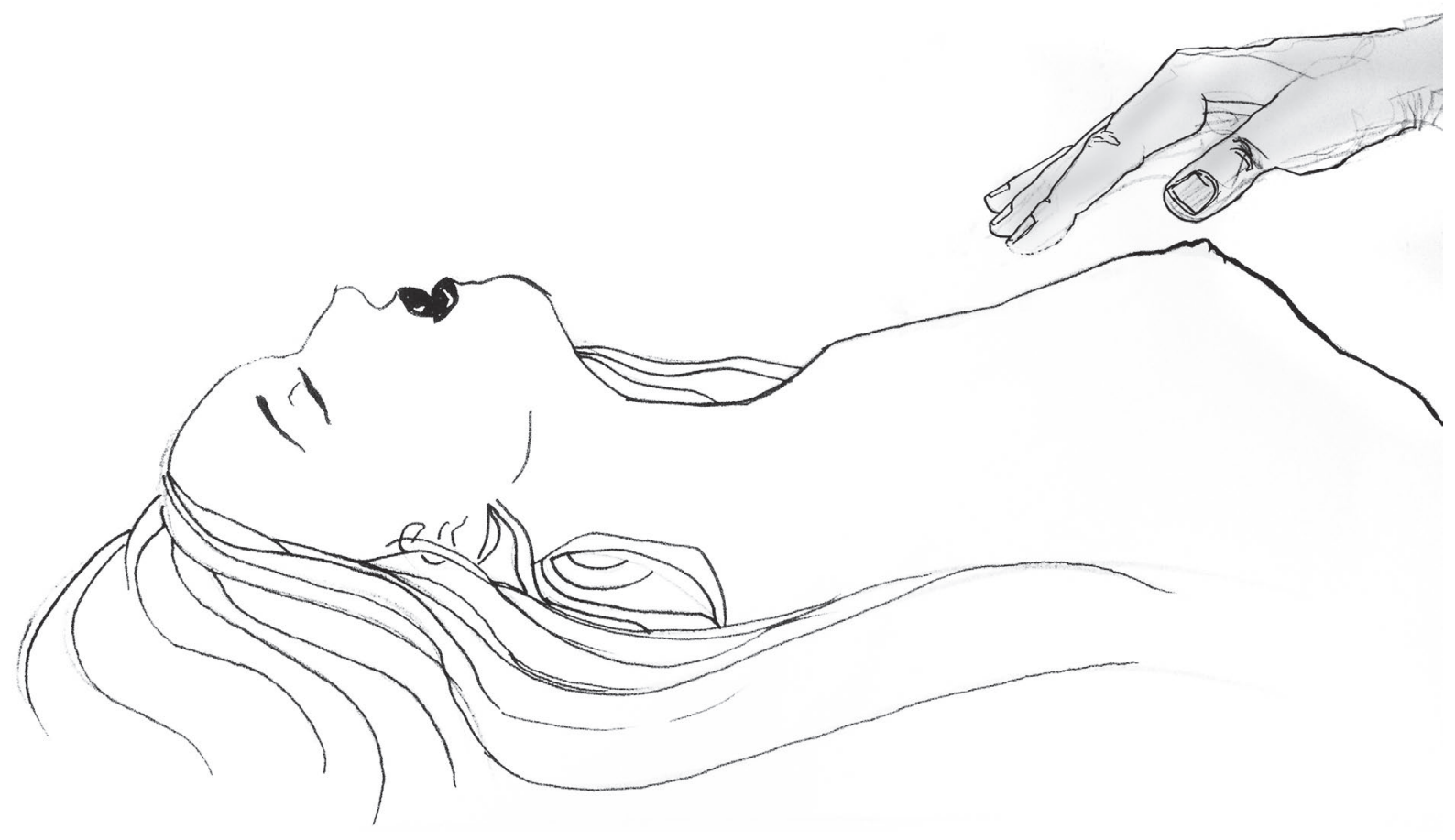




\section{Software y cultura escrita alfabética: una dimensión clave para comprender las transformaciones}

El libro de Manovich motiva a pensar -de manera aún más acotada- las condiciones en las que se lleva la escritura en la actualidad. No es suficiente con considerar la incidencia que trae para la cultura escrita su presencia en el ciberespacio. Es necesario analizar la manera particular como el funcionamiento del software (los recursos que brinda o las limitaciones que impone) incide en la cultura escrita, en cuya conceptualización se integran las herramientas, los conocimientos y las prácticas en una permanente interrelación.

El software abarca las distintas esferas de la sociedad, y este es un hecho al que no puede sustraerse la cultura escrita. Y aunque las transformaciones de la lectura y la escritura no constituyen un asunto que el autor aborde en profundidad, en la siguiente cita menciona la escritura como una de las áreas que están siendo atravesadas e influenciadas por la cultura del software:

"Yo entiendo el software como una capa que impregna todas las áreas de las sociedades contemporáneas. Por lo tanto, si lo que queremos es comprender las técnicas actuales de control, comunicación, representación, simulación, análisis, toma de decisiones, memoria, visión, escritura e interacción, nuestro análisis no podrá considerarse completo si no tenemos en cuenta la dimensión del software. Esto significa que todas las disciplinas que estudian la sociedad y la cultura contemporáneas (la arquitectura, el diseño, la crítica de arte, la sociología, la politología, la historia del arte, los estudios sobre medios, la ciencia y los estudios tecnológicos, y todas las demás) deben incluir en sus disquisiciones la función del software y sus efectos en cualquier temática que investiguen" (Manovich, 2013, p. 33-34).

Desde esa perspectiva, tiene sentido preguntarse por las transformaciones de la cultura escrita en el ciberespacio, considerando las herramientas y posibilidades que el software de medios dispone para los usuarios de las redes sociales. El análisis de los datos acopiados durante el trabajo de campo ha permitido constatar que algunas de las características que adquiere la escritura en la actualidad tienen relación con lo que el software permite y exige al momento de leer y escribir.

Como él mismo lo declara en su libro, tres son las cuestiones que el autor pretende resolver (Manovich, 2013, p. 70): (1) La ideas y motivaciones de quienes entre las décadas de los 60 y de los 70 sentaron las bases conceptuales y técnicas para el software cultural de nuestros días. (2) La transformación en el concepto de medios a partir de la adopción de métodos de producción basados en software. (3) La incidencia de las interfaces y las herramientas de software en la estética y los lenguajes visuales que se observa en el diseño y los medios contemporáneos. Todo lo anterior se articula a la importancia que concede a la presencia del software en las sociedades desde hace seis décadas: 
Yo defiendo que, en el proceso de translación de las tecnologías de medios físicos y electrónicos a software, todas las técnicas y herramientas que anteriormente eran exclusivas de distintos medios 'se reunieron' en el mismo entorno de software. Esta confluencia tuvo una repercusión esencial para el desarrollo de la cultura humana y la evolución de los medios. Fue un revulsivo y un motor de transformación de todo el panorama tecnológico de los medios, los profesionales creativos que los utilizan y el mismo concepto de medio (Manovich, 2013, 73-74).

Y aunque como parte de los propósitos de su libro no está la conceptualización de la cultura escrita ni la relación de ésta con el desarrollo del software, el cruce entre sus planteamientos y los hallazgos de la presente investigación no solamente es posible sino necesario.

\section{Lo que el software simula: de la manipulación de herramientas a la construcción e interpretación de enunciados}

Dentro de la conceptualización de Manovich, resulta clave el concepto de simulación, pues ésta marca uno de los hitos derivados de la invención del "metamedio ordenador". Determinar qué es lo que simula el software de medios - para el caso de la escritura y la lectura- permite entender el lugar de los conocimientos procedimentales de la cultura escrita cuando se lee y se escribe a través de la interface de un software y la incidencia que probablemente tenga en tales conocimientos el uso del software presente en las redes sociales.

Pero ¿qué entraña la simulación de medios físicos por parte del software? En palabras de Manovich,

Lo que el software simula son las técnicas físicas, mecánicas o electrónicas empleadas para navegar, crear, editar e interaccionar con los datos de los medios. Por ejemplo, la simulación de la imprenta incorpora las técnicas de escritura y corrección de textos (copiar, cortar, pegar, insertar); las técnicas de modificación de la apariencia de este texto (cambiar fuentes o el color del texto), así como la maquetación del documento (definir márgenes, insertar números de página, etc.) y las técnicas de visualización del documento final (ir a la siguiente página, visualizar múltiples páginas, usar el zoom, marcar página). (...) En resumen, simular un medio en software significa simular sus herramientas e interfaces, más que su material (Manovich, 2013, p. 261-261). 


\section{Y agrega:}

(...) la simulación en software sustituye toda una serie de materiales

y herramientas utilizados para inscribir información (por ejemplo,

haciendo marcas) sobre estos materiales por un nuevo medio híbrido

a partir de una estructura de datos común. Debido a esta estructura común, ahora podemos emplear conjuntamente diversas técnicas que en el pasado eran exclusivas de un medio específico. Al mismo tiempo, podemos añadir también otras técnicas de nueva creación, siempre y cuando puedan operar sobre la misma estructura de datos" (Manovich, 2013, p. 266).

Dentro del marco teórico de esta investigación, se define la escritura como una tecnología de la información y la comunicación (Ulloa y Carvajal, 2006). Cabe entonces preguntarse: ¿Cómo encaja en dicho concepto la presencia del software en tanto simulador de los materiales y las herramientas para escribir (es decir, para crear y editar textos), así como para leer lo escrito (o sea, navegar en los textos e interaccionar con ellos)?

Escribir y leer implican el ejercicio de conocimientos procedimentales específicos ${ }^{6}$, que se diferencian del dominio de las técnicas físicas, mecánicas o electrónicas simuladas por el software. Editar e interaccionar con datos de medios -cuando se trata de la cultura escrita alfabética- también trasciende el dominio de las herramientas del software. El software proporciona instrumentos y recursos, pero al simularlos no está sustituyendo los conocimientos necesarios para leer y escribir. Por el contrario, cuando se lee y se escribe, los conocimientos procedimentales que involucra el manejo de un software se ponen en marcha a partir (y, podría decirse, en función de) los conocimientos procedimentales de la cultura escrita.

Así como en la cultura del libro el impresor o el tipógrafo no son los que escriben (es decir, no son quienes construyen los enunciados que componen el texto a ser impreso), el software que permite transcribir, editar el texto y navegar por él tampoco es - en sí mismo- el que crea el texto escrito. Esto parece muy obvio, pero es necesario mencionarlo. Lo que simula el software no es la escritura como tal, sino los soportes y las herramientas asociados a ella: los soportes impresos (la hojas de papel que conforman el libro, el periódico o la revista) son reemplazados por el soporte digital (la pantalla); los instrumentos para inscribir, modificar o destacar los enunciados (el lápiz o el bolígrafo, la máquina de escribir mecánica o eléctrica, el borrador, las tijeras, el resaltador) son sustituidos por las teclas, el ratón, la pantalla táctil, las herramientas para cortar y pegar, el resaltado de texto, el tipo y color de fuente, etc.

Este estudio reconoce que escribir y leer en escenarios como el chat, el Facebook y el Twitter significa ejercitar habilidades para interactuar con un software determinado y potenciar las herramientas que éste ofrece. Sin embargo, sostiene que los conocimientos procedimentales de la cultura escrita no quedan subsumidos en el dominio de los conocimientos procedimentales asociados al software para escribir 
y leer en los escenarios mencionados. Con lo anterior no se desconoce que el

ciberespacio, y el entorno de software específico en que se lleva a cabo la lectura y la

escritura en internet, inciden de algún modo en las maneras de escribir y de leer, como

intentará mostrarlo el análisis de los datos acopiados (actualmente en curso).

\section{Software de medios: más allá de la digitalización}

Según Manovich, la palabra "digital” ha sido utilizada por académicos, artistas y periodistas para describir en qué radica la particularidad de los nuevos medios frente a los llamados medios tradicionales o antiguos. El término es empleado para cobijar en una categoría "toda la gama de nuevas tecnologías, nuevas posibilidades expresivas y comunicativas, nuevas formas de comunidad y sociabilidad que han ido emergiendo alrededor de los ordenadores e internet” (Manovich, 2013, p. 198).

No obstante, para el autor

Ninguna de las técnicas de autoría y edición de nuevos medios que asociamos con los ordenadores es sencillamente el resultado de la 'digitalización' de un medio. Todas las nuevas maneras de acceder, distribuir, analizar, generar y manipular los medios proceden del software. Y esto también implica que son fruto de una serie de elecciones particulares de personas, empresas y consorcios que desarrollan el software (Manovich, 2013, p. 199).

(...) las técnicas, las herramientas y las convenciones de las aplicaciones de software de medios no son fruto del cambio tecnológico de 'analógico' a 'digital'. El paso a lo digital permite el desarrollo de software de medios, pero no limita la dirección en la que se había desarrollado y sigue evolucionando. Son fruto de las ideas intelectuales de las personas que las concibieron originalmente (Sutherland, Engelbart, Kay, etc.), los mismos productos creados por las empresas de software y las comunidades de código abierto, los procesos culturales y sociales establecidos por muchas personas y empresas que empezaron a utilizarlos y las fuerzas y restricciones del mercado del software (Manovich, 2013, 201).

Manovich conduce su planteamiento a un punto aún más radical:

Para resumir este aspecto, me permitiré una declaración arriesgada. Los 'medios digitales' como tal no existen. Tan sólo existe el software, tal y como se aplica a los medios (o 'contenidos') ${ }^{7}$. O visto desde otra óptica: para los usuarios que únicamente interaccionan con el contenido de los medios a través del software para aplicaciones, las 'propiedades' de los medios digitales vienen definidas por el software determinado y no están contenidas sencillamente en el contenido en cuestión (es decir, dentro de los archivos digitales) (Manovich, 2013, p. 204). 
Teniendo en cuenta o anterior, y para efectos de lo que interesa en el presente trabajo, ¿podría afirmarse que la "escritura digital”, como tal, no existe?Y, por lo tanto, ¿deberíamos hablar de escritura "software-mediatizada" o "softwarizada" en lugar de "escritura digital”?

Trasladando el planteamiento de Manovich al ámbito de la escritura, cuando creamos textos en el ordenador o conectados a la red, empleando para ello un software específico, los datos que son guardados y organizados en una estructura de datos ${ }^{8}$ corresponden a los enunciados producidos, al discurso elaborado a partir de la puesta en marcha de un conjunto de conocimientos procedimentales para escribir (correspondientes a la dimensión lingüística y a la dimensión discursiva de la escritura) (Ulloa y Carvajal, 2006). El software, por su parte, lo que hace es simular las herramientas para escribir, y operar con ese tipo concreto de datos, es decir, con los textos alfabéticos.

En el caso particular de las redes sociales, lo que existe es un conjunto de software que permite crear, editar y compartir o publicar, así como acceder a lo creado por otros, modificarlo o remezclarlo y ponerlo de nuevo a circular. La escritura-como tecnología de la comunicación y la información- sigue operando con sus propios conocimientos semánticos (saber qué) y procedimentales (saber hacer), pero en un entorno que simula sus antiguas herramientas para la "inscripción" y posibilita técnicas antes inexistentes que promueven y exigen conocimientos procedimentales ligados al dominio del software.

Ahora bien, si según Manovich un software (y los conocimientos procedimentales necesarios para su uso) opera independientemente de los datos que procese (o sea, independientemente del contenido), podría decirse que los conocimientos procedimentales de la cultura escrita están determinados y se ponen en ejercicio independientemente de los materiales, las herramientas y los recursos que se utilicen para escribir. Esto, en principio es así. Pero la confluencia de ambos tipos de conocimientos procedimentales no deja incólumes ni al software ni a la cultura escrita. Los diseñadores de software cada vez tratan de sofisticar las herramientas que ofrecen al usuario, bien para contribuir a que los usuarios escriban conforme a la norma lingüística, bien para responder a demandas sociales dentro de las cuales se inscriben la lectura y la escritura ${ }^{9}$. La cultura escrita, a su vez, se ve inmersa en una serie de dinámicas antes desconocidas: la posibilidad de la comunicación sincrónica vía chat, la economía del lenguaje propiciada por el Facebook y el twitter, la escritura colaborativa en red, la posibilidad de integrar recursos expresivos diferentes a la escritura alfabética, etc., afectan en diferentes grados las formas en que las personas leen y escriben en el escenario de las redes sociales.

Teniendo en cuenta lo anterior, la investigación doctoral en la que se inscribe el presente artículo pretende contribuir a identificar los cambios en los conocimientos, las prácticas y los conceptos de la cultura escrita en el ciberespacio y su posible relación con la puesta en práctica de conocimientos procedimentales ligados al software que soporta la redes sociales. 


\section{La softwarización de la escritura: ¿desde dónde y hasta dónde?}

Si el software ha permeado casi todos los ámbitos de la sociedad - entre ellos la cultura escrita- cabría preguntarse ¿hasta dónde lo ha hecho? Dicho de otro modo, ¿en qué niveles la escritura se ha "softwarizado”? ¿Hasta dónde llegan los conocimientos procedimentales para manejar los recursos del software y desde dónde operan los conocimientos procedimentales para escribir y leer canónicamente? ¿Existe una frontera definida entre ambos?

Tomando como referencia a Manovich, puede afirmarse que la escritura es un medio (tecnología de información y comunicación) y como tal constituye un contenido del metamedio ordenador, conformado por herramientas y materiales, prácticas y conocimientos semánticos y procedimentales (estos últimos, conceptos propios del presente proyecto de investigación). Al ser implementada dentro del entorno de un software: (1) sus herramientas son simuladas, (2) sus conocimientos son puestos en marcha mediante la utilización de recursos del software y por lo tanto en asocio con los conocimientos procedimentales que implica el uso del software; (3) sus prácticas pueden tener alcances que antes no tenían. La confluencia de ambos tipos de conocimientos procedimentales (los de la cultura escrita y los del software) dan lugar a modificaciones al interior de la cultura escrita | que abarcan sus tres componentes: herramientas, prácticas y conocimientos, los cuales son objeto de la investigación en curso.

Para Manovich, "el software de medios afecta a

todo el contenido de medios por igual, independientemente de su estética, semántica, autoría u origen histórico" (Manovich, 2013, p. 167). Este estudio relativiza tal afirmación, pues reconoce que existen relaciones de tensión entre lo que el software promueve y el canon de la escritura alfabética occidental.Dentro del corpus analizado, dichas tensiones se manifiestan en rasgos como: (a) El predominio de formas o estilos idiosincrásicos de escritura, que por ser irregulares e inconsistentes, se alejan de lo canónico. Esto se expresa, por ejemplo, en los usos no canónicos del alfabeto, en las tergiversaciones intencionadas de la ortografía o en la fragmentación arbitraria de los mensajes. (b) La

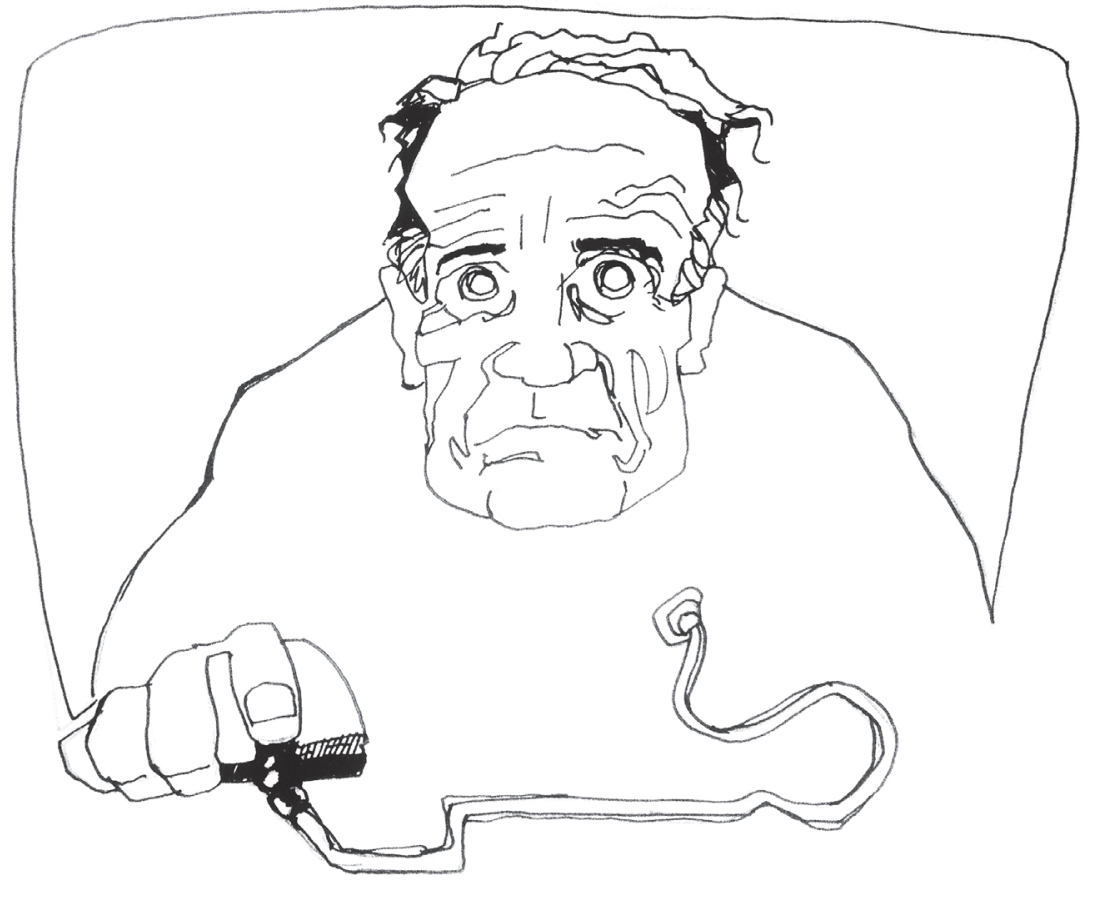


sustitución de los signos de puntuación por recursos proporcionados por el software como la fragmentación de los mensajes, el uso de los emoticones y la representación de la risa mediante onomatopeyas.

(c) La escritura de corte inmediatista, en la que los mensajes dependen de un contexto particular, posterior al cual pueden carecer de sentido. (d) La permisibilidad y tolerancia frente a lo implícito. (e) El régimen de lo prediseñado que resulta funcional a la escritura veloz (emoticones, gifs ${ }^{10}$ y memes ${ }^{11}$ que "hablan" por los sujetos que interactúan en las redes sociales). (f) El papel del software como operador / interface para la ejecución de actos de enunciación, en la medida en que toma la voz para referir lo que hacen y piensan los sujetos que interactúan en escenarios como el Facebook el Twitter.

Desde la perspectiva de la investigación, el software (sus herramientas, sus recursos y el ambiente que proporciona para crear y modificar contenidos y acceder a ellos) está en un nivel distinto del contenido. Mientras el primero opera con un conjunto de datos que son procesados y manipulados mediante algoritmos, el segundo hace parte de los datos con los que opera el software (los textos alfabéticos), los cuales son generados por quien escribe poniendo en ejercicio sus conocimientos procedimentales para hacerlo.

Usar un software para aplicaciones ligado a la cultura escrita no significa operar directamente con el canon de la escritura, sino utilizar los recursos dispuestos por el software -a través de una interfaz- para poner en ejercicio los conocimientos procedimentales de la cultura escrita. Salvo los casos en los que el usuario decide utilizar recursos del software para ahorrarse la necesidad de construir enunciados (por ejemplo los stickers, las etiquetas, los emoticones o los enunciados "prediseñados" para indicar "estados", lugares, etc.), el usuario de las redes sociales que se comunica por medio de la escritura alfabética, tiene que operar con el medio como tal (la escritura) y esto no lo puede sustituir el software. Este último simula la inscripción en el papel o la transcripción en la máquina de escribir mecánica o electrónica y realiza operaciones algorítmicas que permiten indicarle al usuario si hay errores gramaticales o de ortografía en correspondencia con una base de datos acorde con el canon de la escritura alfabética. En ese sentido, las herramientas que provee el software apoyan al usuario para que escriba de acuerdo a la norma gramatical y ortográfica e incluso le hacen sugerencias para mejorar el estilo (por ejemplo, recomienda sinónimos en caso de que se repitan palabras). Pero hay niveles de la producción escrita que rebasan los alcances del software, como lo muestran algunas interacciones que constituyen el corpus de la investigación.

Si bien para Manovich "los medios se convierten en software" (Manovich, 2013, p. 210), en lo que respecta a la lectura y la escritura existen una serie de conocimientos procedimentales -configurados históricamente y adquiridos en contextos culturales particulares- que el sujeto debe poner en práctica y que no son simulados, reemplazados o ejecutados por el software. 
Al respecto, Noah Wardrip-Fruin (2009, citado por Manovich, 2013, p. 145) en la introducción de su libro Expressive Processing, habla de la "especificidad 'metagenerativa' de los ordenadores" y menciona lo que éstos permiten con relación a la escritura: simulan una máquina de escribir; ofrecen diversos tipos de fuentes, corrección ortográfica automática, desplazamiento entre diferentes secciones del documento, programar transformaciones (v.g. buscar y reemplazar), y posibilitan la autoría colaborativa a partir de la disposición de los recursos técnicos para que ésta sea posible. Es evidente que ninguno de estos recursos sustituye o subsume los conocimientos procedimentales de la cultura escrita. Ambos tipos de conocimientos procedimentales -los del software y los de la cultura escrita- coexisten en las prácticas de lectura y escritura en el ciberespacio, y las transformaciones que se están derivando de dicha coexistencia son - precisamente- materia de la investigación.

Las operaciones que el software permite a la hora de realizar tareas de escritura o de lectura se relacionan con las formas de visualización, el formato y la organización de módulos del contenido (por ejemplo cortar, copiar y pegar). Lo que tiene que ver con escribir y leer en sentido estricto - es decir con los conocimientos procedimentales de la cultura escrita- no lo resuelve por sí mismo el software. Incluso con el apoyo que brinda la revisión ortográfica y gramatical o la herramienta para elaborar resúmenes, el sujeto que maneja el software tendría que saber si la palabra "corregida" por éste es correcta en el contexto de su enunciado o si el resumen que el software le propone corresponde a la organización macroestructural del texto que está elaborando.

Definitivamente, no bastará con apoyarse en los recursos que su ordenador le ofrece. Como parte de su grado de adscripción a la cultura escrita, el sujeto estará o no en capacidad de utilizar los recursos que el software le proporciona (y que le exigen un "saber hacer" de su parte) a partir de sus propios conocimientos procedimentales para leer y escribir. El modo como se conjugan ambos tipos de conocimientos en las prácticas de escritura de los sujetos de la investigación, la manera como las herramientas y recursos ofrecidos por el software se convierten en "potenciadores" o "inhibidores" de ciertos conocimientos procedimentales de la cultura escrita y sus cánones son objeto de interés de la investigación.

\section{Software, modelos mentales y transformación en los conceptos de lectura y escritura}

En tanto programa informático, el software de medios está constituido internamente por un conjunto de algoritmos que trabajan sobre estructuras de datos. Además del "saber hacer" implicado en el uso del software, la conjunción de algoritmos y de estructuras de datos define "un modelo mental que tiene el usuario de la aplicación”, esto es, la manera como él entiende "lo que la aplicación le ofrece" y lo que él mismo puede hacer al utilizarla (Manovich, 2013, p. 273). Manovich también denomina a esto "experiencias de usuario", las cuales "alientan una serie de conductas de medios también diferentes (compartir la ubicación, trabajar, chatear, etc.)" (Manovich, 2013, p. 303). 
Para el autor,

La experiencia del usuario sigue definiéndose tan solo en parte por el contenido y la organización del archivo. El usuario es libre de navegar por el documento y elegir tanto qué información visualiza como la secuencia en la que la consulta. Y aunque los 'antiguos medios' (con la excepción de la radiodifusión del siglo XX) también ofrecían ese acceso aleatorio, las interfaces de los reproductores/visores de medios impulsados por software proporcionan muchas más vías de navegar por los medios y seleccionar a qué accedemos y de qué manera (Manovich, 2013, p.64).

Afirmar que la experiencia del usuario está determinada sólo de manera parcial por el contenido y la organización del archivo evidencia la importancia que Manovich le concede al software. Sin desconocer ello, la presente investigación sostiene que los conocimientos procedimentales de la cultura escrita que intervienen en la producción y lectura de textos en el ciberespacio ocupan un lugar capital. Aunque el software (es decir lo que "sabemos hacer" con él) es determinante en la experiencia del usuario, esta experiencia no está desligada - en el caso de la lectura y la escritura- del grado de adscripción a la cultura escrita por parte de sujetos particulares. En el cruce de ambas perspectivas (la que concede un valor preponderante al manejo del software y la que destaca la puesta en marcha de los conocimientos procedimentales de la cultura escrita) esta investigación intenta indagar por las transformaciones que se producen en los conocimientos procedimentales para escribir y leer canónicamente, como resultado de leer y escribir en un entorno de recursos y herramientas proporcionado por el software de medios. En ese sentido, restituye la importancia de tales conocimientos frente a una mirada que se centra únicamente en los conocimientos procedimentales del software que actúa como entorno para la escritura en el ciberespacio.

Aunque lo planteado por Manovich respecto al modelo mental definido por el software es válido, aquí se plantea que el uso dado al chat, al Facebook y al Twitter no está determinado únicamente por dicho modelo. Como se vislumbra en el análisis de los datos, la relación de los sujetos con la cultura escrita (es decir, su nivel de adscripción a ella) es un factor que incide de manera sustancial en el modo como escriben y leen los sujetos de la investigación y en la manera como potencian los recursos y se adecuan a las determinaciones del software.

Por otro lado, el "modelo mental" descrito por Manovich se relaciona con los significados actuales de leer y escribir, conceptos que se transforman a la par que lo hacen los conocimientos y las prácticas de la cultura escrita. Resulta pertinente cuestionarse sobre lo que sucede cuando ese "modelo mental" derivado de la escritura en el chat, el Facebook o el twitter se traslada a otras situaciones de escritura distintas (como la escritura académica, por mencionar alguna). Escribir en estos tres escenarios está determinado en cierta medida por los recursos proporcionados por el software, así como por las limitaciones que éste impone (aunque, como ya se dijo, los modos de 
escribir y de leer estás asociados de manera directa con la historia personal y las relaciones que los sujetos han establecido con la cultura escrita en distintos espacios). Sin perder de vista que el sujeto reconoce, además, aspectos importantes para la comunicación como el tipo de interlocutores o la intención que motiva las interacciones, el software y el "modelo mental" que éste promueve en el usuario podrían incidir en la manera como los sujetos conciben lo que significa leer y escribir.

En ese sentido, el libro de Manovich permite ahondar en las diferencias que hay entre escribir sobre el papel (a mano o utilizando la máquina de escribir), escribir en la pantalla de un ordenador y, de modo más particular, producir textos en y para las redes sociales dentro del ciberespacio. La escritura en el computador o en la red probablemente dé lugar a tensiones frente al canon, así como al surgimiento de nuevos conocimientos procedimentales de la cultura escrita y al desplazamiento de otros. Una cita del Manovich resulta sugerente al respecto:
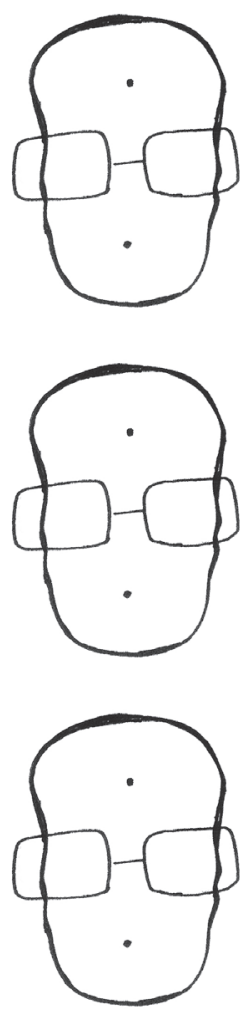

En el entorno de la aplicación, un usuario trabaja con uno o más documentos que tienen su propio contenido estructurado de forma determinada. El usuario es consciente de la importancia de esta estructura, aunque las aplicaciones no utilicen el término 'estructura de datos'. El usuario entiende que la estructura de datos determina el tipo de contenido que puede crear y las operaciones que pueden emplearse para

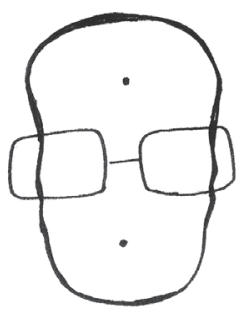
conformarlo o modificarlo (Manovich, 2013, p. 273).

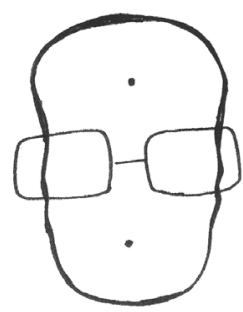

Lo anterior, en términos del marco teórico de la investigación, constituye un conocimiento semántico y un conocimiento procedimental que se cruzan con los conocimientos semánticos y procedimentales de la cultura escrita: qué es viable y qué no lo es -desde las determinaciones del software- , y saber cómo realizarlo (desde las determinaciones del canon de la cultura escrita alfabética) constituye un lugar donde confluyen las aplicaciones de software para escribir en la red y el grado de adscripción a la cultura escrita por parte de los sujetos.

Como se ve en las interacciones del corpus, el concepto actual de escritura

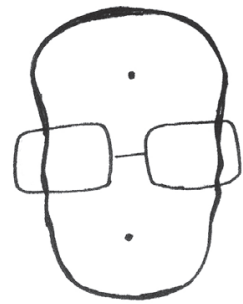
puede llegar a involucrar diversas prácticas: usar recursos expresivos distintos al alfabeto y los signos de puntuación (por ejemplo los stickers o los emoticones); emplear textos prediseñados que el software pone a nuestra disposición; escribir de manera fragmentada, en lugar que de manera continua; sustituir signos de puntuación por risas, emoticones o por el uso del espaciador (tecla “enter" o "intro”); comentar videos o imágenes publicadas; resolver desfases en la continuidad de los mensajes generadas en la escritura dentro del chat; marcar el mensaje con un "hashtag", estableciendo así relaciones con otros mensajes asociados a una misma temática y marcando la macroestructura del mensaje y su contexto, etc. 

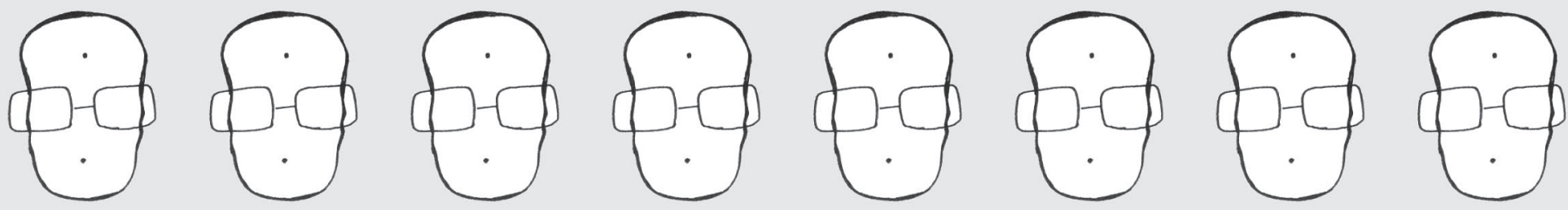

\section{Hacia un cambio conceptual: del dominio del software al dominio de la cultura escrita}

Una de las preguntas que intenta resolver Manovich en su libro es ¿qué son los medios hoy y cómo están siendo definidos por las aplicaciones de software para su creación y edición? Una de las respuestas que esboza en el capítulo 4 dice: "Tal y como lo define el software para aplicaciones, y como lo experimentan los usuarios, un 'medio' es un encaje de una estructura de datos concreta y los algoritmos para la creación, edición y visualización de los contenidos almacenados en esa estructura" (Manovich, 2013, p. 278). A partir de esta definición y atendiendo a lo dicho por el autor con relación a la escritura como medio y contenido del metamedio ordenador, se podría hablar aquí -tentativamente- de la escritura softwarizada (o escritura apoyada en el software), como el ensamblaje entre una estructura de datos (que corresponden a los textos construidos) y los algoritmos que permiten crear, modificar y visualizar esos datos. Es decir, al resultado de la confluencia entre los conocimientos procedimentales para leer y escribir y los conocimientos procedimentales para operar los algoritmos (no visibles al usuario) a través de la interface del software y generar nuevos datos que corresponderían a los textos con una determinada organización y un determinado formato. El software aporta a los usuarios herramientas de inscripción y edición para crear textos (datos) que pueden ser modificados y visualizados. Con respecto a la lectura, les da recursos para recorrer la información con diferentes formas de visualización, posibilidades de búsqueda e intervención (resaltar, comentar, fragmentar) y recursos para compartirla con otros usuarios. En ese sentido, existiría una escritura softwarizada o escritura del software, dado que escribir en el ordenador y en el ciberespacio exige el dominio del software a través de una interface (teclado, ratón, pantalla, íconos, carpetas, comandos de voz, etc.). Este dominio sería lo específico en ella, como existe un modo específico de operacionalización de la escritura manuscrita (asociado a las formas caligráficas) o de la escritura impresa (que como ya se mencionó es del resorte de los especialistas impresores o tipógrafos). Ahora bien, como ya se ha dicho, el dominio del software no sustituye los conocimientos procedimentales para leer y escribir. La cultura escrita dentro del entorno del software no se agota en el uso de las herramientas y el dominio de la interfaz (como tampoco se agotaba en el uso de la caligrafía, la máquina de escribir o la imprenta) sino que sigue teniendo una especificidad. Pero la llegada del software a la cultura escrita no la deja indemne: ella continúa con una transformación iniciada desde el momento en que la palabra escrita emergió y se fue consolidando. Por ello, se hace necesario identificar los cambios que se están dando en los modos de escribir y leer, considerando las distintas dimensiones de la cultura escrita (las herramientas, los conocimientos y las prácticas). 


\section{Cultura escrita y software: relaciones mutuas}

Así las cosas, como lo señala el mismo Manovich, los medios que han sido “implementados en los programas de software" entran a formar parte

de las diversas historias culturales, que se remontan a centenares e incluso miles de años (...) Un medio (...) no es tan solo un grupo de materiales y herramientas (físicas, mecánicas, electrónicas o trasladadas a software) y técnicas artísticas soportadas por esas herramientas; también es una base de datos imaginaria de todas las posibilidades expresivas, composiciones, estados emocionales y dinámicas, técnicas de representación y comunicación, y 'contenido' materializado en todas las obras creadas combinando determinados materiales y herramientas" (Manovich, 2013, p. 297).

La cultura escrita no escapa a esta dinámica histórica, de tal modo que "el texto electrónico forma parte de la historia de la escritura” (Manovich, 2013, p. 297) (diríase aquí, en términos del presente proyecto, de la historia de la cultura escrita). Lo importante de este señalamiento es reconocer, como lo hace el autor, que las historias, bien sea de la escritura o de la imagen "influyen en nuestra visión de los medios hoy en día y [en] el uso que les damos" (Manovich, 2013, p. 297). De igual manera, la relación de los sujetos con la cultura escrita a lo largo de su historia personal habrá de incidir en el modo como usen el software para escribir en el ciberespacio.

En síntesis, en la cultura escrita softwarizada del ciberespacio confluyen los conocimientos procedimentales asociados al software interactivo de medios con aquellos que permiten leer y escribir canónicamente. La confluencia de estos tipos de conocimientos está generando cambios en los modos de leer y de escribir, en lo que se define hoy como lectura y escritura y en las habilidades y conocimientos que se ponen en juego en las distintas prácticas de la cultura escrita. De otra parte, la escritura softwarizada se inscribe en la historia del sujeto y de su relación con la cultura escrita, así como la escritura con software forma parte del universo amplio que constituye la cultura escrita. Por lo tanto la ecuación podría invertirse: no es la cultura escrita la que se inserta en el ciberespacio y en un entorno específico de software de medios; es el software el que con sus recursos penetra el ámbito de la cultura escrita, y lo hace en su condición de metamedio con presencia totalizadora (omnipresencia) en la cultura. ¿Qué sucede, entonces, con la lectura y la escritura en ese encuentro de dos mundos?

Los conocimientos procedimentales del software y los conocimientos procedimentales de la cultura escrita son diferenciables. Los primeros no reducen a los segundos y los segundos (cuando se trata de escribir en el ciberespacio) no operan independientemente de los primeros. No obstante, su diferenciación no impide reconocer el modo como su confluencia está dado lugar a rasgos emergentes de leer y escribir que contribuyen a reconfigurar las prácticas y a modificar los significados de la lectura y la escritura hoy. 


\section{La cultura escrita en la sociedad del software: síntesis e interrogantes}

La metáfora empleada por Manovich para titular su obra recoge la esencia de su planteamiento. Como él lo expone a lo largo del libro, al tomar el mando el software abarca todos los ámbitos de la sociedad y su incidencia es algo que no tiene marcha atrás. En palabras suyas, "el software reajusta y configura todo aquello donde se aplica o, al menos, puede llegar a hacerlo” (Manovich, 2013, p. 56). ¿Qué sucede en este contexto con la cultura escrita, tema que atañe a la presente investigación?

La cultura escrita no escapa a la influencia que tiene el software en la sociedad y en la cultura. El software entra a formar parte de la cultura escrita desde el momento en que empieza a simular sus herramientas y a tener efecto sobre sus conocimientos y sus prácticas. Ahora bien, ello ha traído como consecuencia que tiendan a confundirse los saberes necesarios para operar las herramientas proporcionadas por el software y los conocimientos necesarios para leer y escribir. De ahí la necesidad de distinguir entre unas y otros: una cosa son los conocimientos procedimentales del software y otra cosa son los conocimientos procedimentales de la cultura escrita. La confluencia de ambos tipos de conocimientos al leer y escribir en escenarios como el Chat, el Facebook y el Twitter ${ }^{12}$ no implica desconocer sus diferencias, fundamentales a la hora de entender las transformaciones de la cultura escrita en el ciberespacio.

También es necesario, en el cierre de este artículo, mencionar que la lectura del libro de Manovich hace visible una dimensión del problema de investigación que hasta antes permanecía oculta: los rasgos del ciberespacio (plasticidad, fluidez, velocidad, interconectividad, multimedialidad, hipertextualidad, interactividad, virtualización, desterritorialización) (Carvajal, 2012) que posiblemente incidan en la escritura y la lectura realizada en la red provienen del software y son consecuencia de las propiedades de este último. No existe la cultura escrita en el ciberespacio "a secas". Existe la cultura escrita mediada por el software en el ámbito ciberespacial. Por ellos, es necesario insistir en una dimensión clave para el problema de investigación: no es la cultura escrita la que ingresó en el ciberespacio. Es el software el que ha extendido su presencia hasta abarcar la escritura y la lectura, permeando la cultura escrita en su conjunto, empezando a ser parte de ella y conduciéndola a espacios antes impensables en épocas como la del manuscrito o la imprenta.

A lo largo del artículo se han formulado algunos interrogantes derivados de la conceptualización de Manovich. A continuación se retoman algunos de ellos, como una manera de sintetizar asuntos que se ponen en juego al cruzar las transformaciones actuales que se están generando en la cultura escrita con la presencia prominente del software en nuestra sociedad: 
- ¿La posibilidad del software de inventar nuevos medios y no sólo de trabajar con los ya existentes significa algo para el desarrollo de la cultura escrita? ¿Si el software dota de nuevos recursos a los medios que "remedia", esto cómo se ve reflejado en la lectura y la escritura? ¿De qué manera el software está remoldeando la escritura? ¿Cómo afectan los "principios comunes de medios" los conceptos sobre la lectura y la escritura? ¿Cómo contribuye la cultura del software a reconfigurar la cultura escrita?

- ¿Cómo el software afecta la cultura escrita y sus conocimientos procedimentales?

Si en la actualidad la relación con la cultura escrita está siendo mediada (aunque no de manera exclusiva) y remoldeada por el software, ¿esto podría estar configurando nuevas prácticas de lectura y escritura antes inexistentes?

- ¿Cómo están configurando las interfaces y las herramientas de software de medios los modos de leer y escribir de los usuarios del Chat, el Facebook y el Twitter? ¿Lo que las personas viven como la escritura y la lectura en dichos escenarios es -de algún modo- resultado de leer y escribir en un entorno específico determinado por el software? ¿Qué tipo de tensiones se derivan de escribir y leer en las redes sociales y las interfaces proporcionadas por el software que las soporta?

- ¿Qué es lo que cambia en los modos de leer y de escribir y cuáles de esas transformaciones son derivadas de las herramientas de software empleadas para escribir y leer en el ciberespacio? Habiendo sido integrada como contenido del metamedio ordenador (o de los nuevos medios), la escritura (y su correlato: la lectura) adquiere unos rasgos específicos que permiten hablar de una escritura digital-softwarizada-ciberespacial?

\section{Notas}

\footnotetext{
${ }^{1}$ El presente artículo forma parte de la investigación doctoral titulada "Cultura escrita en el ciberespacio ¿Nuevos conocimientos, nuevos conceptos, nuevas prácticas?”, del Doctorado en Ciencias de la Educación - Línea pensamiento Educativo y Comunicación. RUDECOLOMBIA, Universidad Tecnológica de Pereira. La investigación aborda las transformaciones de la cultura escrita en el ciberespacio, manifestadas en las prácticas de escritura emergidas en el chat y las redes sociales, y se pregunta si es posible hablar de una cultura escrita digital o ciberespacial, con unos conocimientos semánticos y procedimentales propios. Se analiza un corpus de textos producidos en Facebook, Twiter y chat, por jóvenes entre 16 y 25 años y adultos mayores de 50, con el fin de comparar casos de sujetos que se han apropiado simultáneamente de la cultura escrita y del ciberespacio (primer grupo) y aquellos que hicieron una transición "tardía” a la escritura en la red. El corpus - conformado por más de 1500 interacciones realizadas de manera espontánea por los sujetos de la investigación- permite identificar la implementación de conocimientos procedimentales propios de la cultura escrita, la emergencia de conocimientos procedimentales asociados al software dentro del ciberespacio y el surgimiento de conceptos sobre la lectura y la escritura. En el análisis en curso se vislumbra la emergencia de unos conocimientos y el desplazamiento de otros, como parte de la transformación de la lectura y la escritura en el ciberespacio, concretamente en los escenarios analizados.
} 
El marco teórico de la investigación incluye la conceptualización sobre cultura escrita, canon de la cultura escrita y conocimientos semánticos y procedimentales (Ulloa y Carvajal, 2006, 2008 a y b, 2011). Dicha conceptualización se fundamenta en Olson (1998) y Williams(1992), así como en la lingüística textual (Chomsky, 1974, 1999; Van Dijk, 1994, 1996), la teoría de la enunciación (Bajtín, 1997; Benveniste, 1977; Austin, 1962; Searle, 1969; Ducrot, 1988) y la psicología cognitiva (Serrano, 2000; De Torres, et. al., 1999). Además, toma como referencia el concepto de ciberespacio acuñado por Lévy (2007) y la teoría del software desarrollada por Manovich (2013), a la que hace referencia el presente artículo.

${ }^{2}$ Profesora de la Escuela de Comunicación Social de la Universidad del Valle. Comunicadora Social, Licenciada en Música y Magíster en Comunicación y Diseño Cultura de la Universidad del Valle. Candidata a doctora en Ciencias de la Educación.

${ }^{3}$ Cada vez que se cite textualmente al autor, se conservarán las cursivas empleadas por él a lo largo de su texto.

${ }^{4}$ Para el autor la categoría "interfaz" cobra un interés particular, específicamente en tres aspectos: [1] las consideraciones de los usuarios sobre las funciones que el software "les ofrece para crear, compartir, reutilizar, mezclar, crear, gestionar, compartir y comunicar el contenido, [2] los interfaces [que] se emplean para presentar esas funciones y [3] las presuposiciones y modelos sobre el usuario, sus necesidades y la sociedad codificados en estas funciones y el diseño de su interfaz" (p. 51).

${ }^{5}$ Con relación al término contenido, el autor hace la siguiente aclaración: Un tipo de contenido de la cultura digital lo constituyen los medios que se crean, se comparten y a los que se accede por medio de un software. Otro tipo de contenido está formado por las herramientas que ofrecen los medios y las páginas sociales: "texto, imágenes, video digital, animaciones, objetos y escenas en 3D, mapas” y combinaciones entre ellos. De igual modo, los contenidos de la cultura digital corresponden a los géneros que hacen presencia en ella, "por ejemplo, páginas web, tuits, actualizaciones de Facebook, juegos ocasionales, juegos multijugador en línea, video generado por los usuarios, resultados de buscadores, URL, ubicaciones en mapas, favoritos compartidos, etc.” (p. 46)

${ }^{6}$ Estos conocimientos constituyen un "saber hacer" en la escritura, tanto en la dimensión lingüística (que incluye las concordancias gramaticales, del empleo de preposiciones y artículos, la propiedad léxica, la ortografía, la puntuación y la coherencia local, entre otros), como en la dimensión discursiva (relacionada con la representación de la fuerza ilocucionaria, el empleo de los marcadores deícticos, la representación de los distintos enunciadores presentes en un enunciado mediante el uso de verbos ilocutivos y construcciones preposicionales y la representación del enunciatario como parte del acto de enunciación). En otras palabras, corresponden a los conocimientos que debe poseer alguien para escribir de acuerdo con el canon de la escritura alfabética, para garantizar que su texto sea comprendido en su ausencia. En cuanto a la lectura, se trata de los conocimientos del lector para leer desde la perspectiva de la organización del texto dada por su autor, contando con su propia cognición social (capacidad para realizar inferencias, identificar enunciadores presentes en el texto, reconocer macroestructuras y superestrusturas textuales -van Dijk, 1996- y recuperar la fuerza ilocucionaria de los enunciados).

${ }^{7}$ Como puede verse a lo largo de su libro, Manovich emplea indistintamente los términos medios y contenidos. Una explicación a ello es que, en su planteamiento, los medios (tradicionales o antiguos) operan como contenidos del metamedio ordenador.

8 "Una estructura de datos se define como "una determinada forma de guardar y organizar datos en un ordenador para su uso eficiente'”. (Dictionary of Algorithms and Dara Structures, citado por Manovich, 2013, p. 263).

${ }^{9}$ Paulatinamente, el software de los procesadores de textos ha ido incorporando recursos como la posibilidad de abrir dos documentos a la vez en ventanas distintas, el seguimiento de cambios realizados a un documento, la introducción de comentarios, los hipervínculos, etc., que en épocas anteriores el usuario realizaba de modo artesanal utilizando papel, lápiz, tijeras, pegante, marcadores de distintos colores, por mencionar apenas un ejemplo. 
10 "GIF" es la sigla del termino técnico "Graphics Interchange Format". Se ha generalizado su uso para nombrar imágenes de personajes famosos, de caricaturas o de gente del común cuyas reacciones fotografiadas o filmadas pueden ser utilizadas al referirse a situaciones de la vida cotidiana con un sentido jocoso y burlesco.

${ }^{11}$ Bajo el término "meme” se engloba un conjunto variopinto de imágenes que van desde la caricatura y el cómic hasta la fotografía, usadas casi siempre con sentido irónico y burlesco. Esta forma de expresión que acompaña el texto escrito se caracteriza por su accesibilidad que permite una utilización oportuna. En muchos de los casos, el uso de imágenes como los memes, las tarjetas electrónicas y otros recursos como los emoticones ayudan a que las personas expresen su manera de pensar o sus sentimientos, cuando no es que hacen innecesaria la producción textual por parte de los sujetos que interactúan en las redes sociales.

${ }^{12}$ Dicho sea de paso, la noción del software como "entrono" (empleada por Manovich a lo largo de su libro) encaja con la denominación de "escenarios" de lectura y escritura, dada al Chat, al Facebook y al Twitter dentro de esta investigación.

\section{Referencias}

Austin, J. L. (1962). How to do things withWords. Cambridge: Oxford.

Bajtin, M. (1997). Marxismo e Filosofía da Linguagem. Sao Paulo: Editora Hucitec.

Benveniste, E. (1977). El Aparato Formal de la Enunciación, en Problemasde Lingüística General II . México: Siglo XXI Editores.

Carvajal, G. (2012). Ciberespacio, educación y cultura escrita. Algunas reflexiones sobre el libro de

Pierre Lévy “Cibercultura. La cultura de la Sociedad Digital”. Nexus(12), 38-63.

Chomsky, N. (1974). Estructuras sintácticas. México: Editorial Siglo XXI.

Chomsky, N. (1999). Aspectos de la teoría de la sintaxis. Barcelona: Gedisa Editorial.

De Torres, J. S. et. al. (1999). Procesos Psicológicos Básicos, . Madrid: Mc Graw Hill.

Ducrot, O. \&. (1981). Diccionario Enciclopédico de las Ciencias del Lenguaje. México: Siglo XXI Ediciones.

Ducrot, O. (1988). Polifonía y Argumentación. Cali: Universidad del Valle .

Havelock, E. (1994). Prefacio a Platón. Madrid: visión distribuciones

Lévy, P. (2007). Cibercultura. La cultura de la sociedad digital. Barcelona: Antropos.

Manovich, L. (2013). El software toma el mando. Barcelona: Editorial UOC.

Olson, D. (1998). El mundo sobre el papel. El impacto de la escritura y la lectura en la estructura del conocimiento. Barcelona: Gedisa.

Ong, W. (1994). Oralidad y Escritura:Tecnologías de la Palabra.Bogotá: Fondo de Cultura Económica.

Searle (1969). Speech Acts. A essay in the Philosophy of Languaje. Cambridge: Cupress.

Serrano, E. (2000). Consideraciones Semióticas sobre el Concepto de Competencia, en El Concepto de Competencia: Una mirada interdisciplinar (Vol. II). Bogotá: Alejandría Libros.

Ulloa, A. \&. Carvajal, G. (2006). Cultura escrita, conocimiento y tecnocultura. El marco teórico de una investigación exploratoria en la Universidad del Valle. Nexus(2), 105-141.

Ulloa, A. \&. Carvajal, G. (2008a). Lectura y Comprensión textual. Entreartes(7), 35 - 49.

Ulloa, A. \&. Carvajal, G. (2008b). Teoría del texto y tipología discursiva. Signo y Pensamiento(53), 295 313.

Ulloa A. \& Carvajal, G. (2011). Cultura escrita y tecnocultura contemporánea: mediaciones cognitivas en la formación universitaria. Nexus(10), 44-65.

Van Dijk, T. (1994). Análisis Crítico del Discurso. Cali : Universidad del Valle.

Van Dijk, T. (1996). La Ciencia del Texto. Barcelona: Ediciones Paidós Ibérica.

Williams, R. (1992). Historia de la Comunicación. Barcelona: Bosch Editorial.

Recibido: octubre 30 / Aprobado: noviembre 20 de 2015 